\title{
Uncovering consistencies in Indian rainfall trends observed over the last half century
}

\author{
Guillaume Lacombe $\cdot$ Matthew McCartney
}

Received: 19 September 2013 / Accepted: 10 December 2013 / Published online: 18 January 2014

(C) The Author(s) 2014. This article is published with open access at Springerlink.com

\begin{abstract}
Food security in India is tightly linked to rainfall variability. Trends in Indian rainfall records have been extensively studied but the subject remains complicated by the high spatiotemporal variability of rainfall arising from complex atmospheric dynamics. For various reasons past studies have often produced inconsistent results. This paper presents an analysis of recent trends in monthly and seasonal cumulative rainfall depth, number of rainy days and maximum daily rainfall, and in the monsoon occurrence (onset, peak and retreat). A modified version of the Mann-Kendall test, accounting for the scaling effect, was applied to 29 variables derived from square-degree-resolution daily gridded rainfall (1951-2007). The mapping of gridded trend slopes and the regional average Kendall test were used concurrently to assess the field significance of regional trends in areas exhibiting spatial homogeneity in trend directions. The statistics we used account for temporal and spatial correlations, and thus reduce the risk of overestimating the significance of local and regional trends. Our results i/ improve available knowledge (e.g. $5 \%$-field-significant delay of the monsoon onset in Northern India); ii/ provide a solid statistical basis to previous qualitative observations (e.g. $1 \%$-field-significant increase/decrease in pre-monsoon rainfall depth in northeast/southwest India); and, iii/ when compared to recent studies, show that the field significance level of regional trends (e.g. in rainfall extremes) is test-dependent. General trend patterns were found to align well with the geography of anthropogenic atmospheric disturbances and their effect on rainfall, confirming the paramount role of global warming in recent rainfall changes.
\end{abstract}

\section{Introduction}

In India, rainfall variability is a central driver of the national economy. Although a considerable volume of Himalayan water flows into India, in situ rainfall is the main resource for agriculture which generates about $20 \%$ of the national GDP (CIA 2012). More than half of the country's population depends on agriculture for their livelihoods. Dry years negatively impact grain production, food security and GDP (Gadgil and Gadgil 2006).

Electronic supplementary material The online version of this article (doi:10.1007/s10584-013-1036-5) contains supplementary material, which is available to authorized users.

G. Lacombe $(\bowtie) \cdot$ M. McCartney

Southeast Asia Regional Office, International Water Management Institute, PO Box 4199, Vientiane, Lao People's Democratic Republic

e-mail: g.lacombe@cgiar.org 
Indian climate is dominated by the southwest Monsoon accumulating $70 \%-90 \%$ of annual precipitation between June and September. The monsoon onset occurs during the boreal spring in response to contrasted warming rates between South and Southeast Asian land regions and the surrounding oceans. Warmer land areas generate a large-scale meridional surface temperature gradient and the establishment of a low pressure region, inducing a northward excursion of the inter-tropical convergence zone (ITCZ), and bringing moisture from the Arabian Sea and the Bay of Bengal toward India. The Himalayan range reinforces this phenomenon by ensuring air heats up to the troposphere. Furthermore, the East African highlands guide the south-north cross equatorial flows aided by the Earth's rotation to form the low-level westerly jet as it approaches South Asia (Turner and Annamalai 2012). During the post-monsoon (October-December), the land mass cools, the ITCZ retreats south bringing dry, cool, and dense Central Asian air masses to India. This marks the transition from wet to dry conditions in most parts of India. However, due to the rain shadow effect and to the north-easterlies collecting moisture over the Bay of Bengal, the extreme southeast peninsula receives reliable rainfall only during the post-monsoon (Ranade et al. 2008). In winter (January-February), most of the country is dry except the extreme southern Peninsula and Northeast India which receive light rainfall. The initiation of the contrasted land-sea warming determines the monsoon onset during the pre-monsoon (March-May) and is marked by a high inter-annual rainfall variability (Ranade et al. 2008).

Inter-annual monsoon rainfall variations are predominantly controlled by the tropical pacific sea surface temperature (SST) anomalies related to El Nino Southern Oscillation (ENSO) (Kumar et al. 2006). At a lower frequency, monsoon variations are tele-connected to the Atlantic multi-decadal oscillation related SST (Kucharski et al. 2009). Anthropogenic climatic changes are believed to be influencing long-term monsoon patterns (Turner and Annamalai 2012) and will likely impact the country's food security and economic development. Against this background, insights into historical rainfall trends are necessary for both agricultural and water development planning. Past studies have investigated rainfall trends across a range of scales from individual stations to the country level (Jain and Kumar 2012). Table 1 summarizes and compares results from the most recent studies which investigated spatial pattern in seasonal cumulative rainfall trends across India. Table 1 reveals a trend of increasing dryness in central India, during the monsoon and the year, over the last century or half century. Patterns of change in other areas, or for other seasons (pre-monsoon, post-monsoon and winter), are less consistent among studies. This heterogeneity could be a consequence of the higher multi-decadal variability of rainfall (Ranade et al. 2008) in peripheral areas, combined with the varying time periods of analysis, the use of different definitions of seasons, different statistical tests, trend slope estimators and spatial units. Other studies (Goswami et al. 2006; Rajeevan et al. 2008; Krishnamurthy et al. 2009; Ghosh et al. 2012) investigated trends in rainfall extremes and show contrasting results about spatio-temporal variability, mainly because of the various definitions of extreme events (Ghosh et al. 2012).

Several observations emerge from this literature review. They point to likely causes of confusion about rainfall trends in India to date:

- spatial units in Table 1's studies are river basins or meteorological divisions with boundaries not necessarily aligning with the pattern of regional rainfall change,

- to the best of our knowledge, the disruptive effect of auto-correlation on trend significance (variance inflation of the test statistic leading to an over-estimation of the trend significance-Cox and Stuart 1955) is not accounted for in any of the referenced studies,

- $\quad$ only a few studies (e.g. Krishnamurthy et al. 2009; Ghosh et al. 2009; Duncan et al. 2013) assessed the field significance of regional trends. They used the binomial approach 


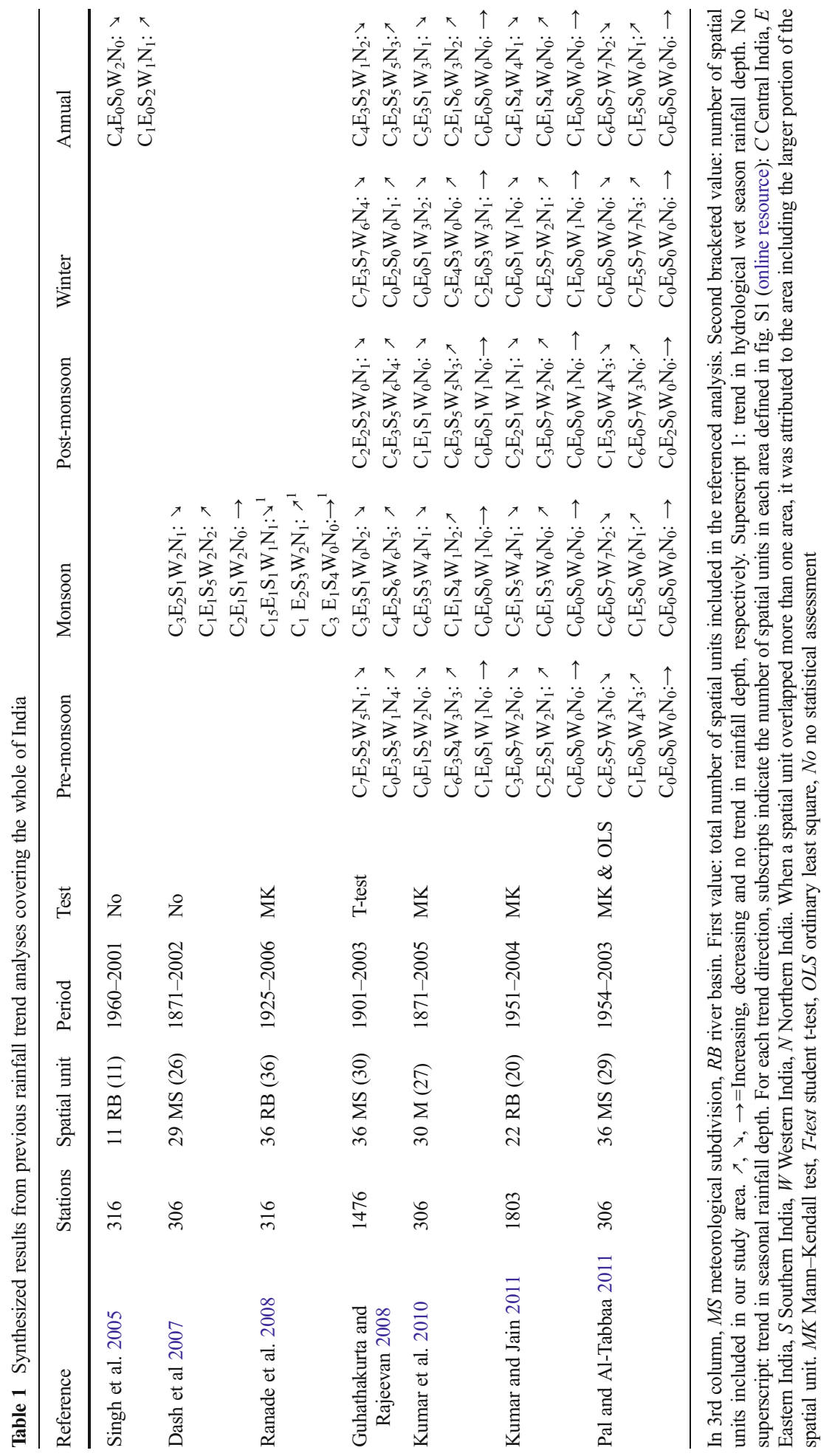


(Livezey and Chen 1983) to verify whether local trends above a pre-defined significance level, and over a given area, occurred by chance. This test overlooks the complete distribution of local trends possibly contributing to a regional uniform and significant signal.

In our study, we mapped high-resolution slopes and statistical significances of local trends in various variables capturing the intensity, frequency and seasonality of rainfall and the occurrence of the monsoon in India, over the last half century. We used a modified version of the Mann-Kendall test (Hamed 2008) accounting for the scaling effect (Hurst 1951; Koutsoyiannis 2003) which denotes the invariance properties of a time series aggregated on different time scales. Accounting for this type of auto-correlation helps discriminating unidirectional trend and multi-decadal cyclic phenomena. In addition, we used the regional average Kendall test (Douglas et al. 2000) to assess the field significance of uniform regional trends (Renard et al. 2008) likely reflecting synoptic atmospheric disturbances. This test accounts for information included in all grid cells of areas exhibiting uniform rainfall changes identified by the high-resolution trend-slope mapping. The methodology is described in section 2. Section 3 presents the results. Section 4 compares the results with previous findings and discusses possible causes of the observed trends.

\section{Data and methodology}

\subsection{Rainfall variables}

The updated version of the quality-controlled $1^{\circ} \times 1^{\circ}$-resolution grid of daily rainfall (Rajeevan et al. 2006) was produced from 1,803 rain gauges with $>90 \%$ data availability during the analysis period (1951-2007). We focused on the main land mass of India $\left(8-32^{\circ} \mathrm{N} ; 68-89^{\circ} \mathrm{E}\right)$, excluding the extreme North and East where the density of rain gauges is extremely low.

Twenty-nine annual variables (online resource, tables S1, S2, S3) were derived from the daily rainfall grid: rainfall depths and the number of rainy days $\left(>1 \mathrm{~mm}\right.$.day $\left.{ }^{-1}\right)$ were calculated for the whole year and for four seasons: winter (January-March), pre-monsoon (April-May), monsoon (June-September) and post-monsoon (October-December). Maximum daily rainfall depth was calculated for the four seasons. Similar variables were calculated for the 4 months of the monsoon: rainfall depths, numbers of rainy days and maximum daily rainfall. It should be noted that including March in the winter rather than the pre-monsoon season has two advantages: a reduced number of zero values (which bias trend significances) in winter time series; an improved representation of pre-monsoon rainfall changes that mainly occur in April and May (cf. Sections 3 and 4). The ordinal dates (number of days since January $1^{\text {st }}$ ) of the monsoon onset and of the monsoon retreat were defined as suggested by Lacombe et al. (2012a): the monsoon onset corresponds to the first day of the first 10-day period of the year that satisfies two conditions: (1) the cumulative rainfall depth of the 10-day period exceeds the mean 10-day rainfall depth of the station, averaged over the period 1951-2007 and (2) at least two of the next three 10-day periods satisfy the same condition. Due to the extreme temporal variability of rainfall, the 10-day rainfall depths were first smoothed by a three time-step moving average. The end of the monsoon was defined by symmetrical conditions, starting from the end of the calendar year and moving backward through the 10-day periods. This way, the definition of the onset and retreat of the monsoon is specific to local rainfall amounts and allows the monsoon occurrence in any cell of the grid, including the driest and wettest areas, to be captured. The monsoon peak was defined as the ordinal date of the first day of the wettest 5-day period. 
2.2 The Mann-Kendall test under the scaling hypothesis

Given a time series $X_{i}(\mathrm{i}=1, \ldots, \mathrm{n})$, the test statistic $S$ of the original Mann-Kendall trend detection test is given by:

$$
S=\sum_{i=1}^{n-1} \sum_{j=i+1}^{n} \operatorname{sgn}\left(X_{j}-X_{i}\right) \quad \text { where } \quad \operatorname{sgn}(\theta)=\left\{\begin{array}{cl}
1 & \text { if } \quad \theta>0 \\
0 & \text { if } \theta=0 \\
-1 & \text { if } \theta<0
\end{array}\right.
$$

The variance $V_{o}(S)$ of the statistic $S$ is calculated as follows:

$$
V_{o}(S)=\frac{n(n-1)(2 n+5)-\sum_{i=1}^{m} t_{i}\left(t_{i}-1\right)\left(2 t_{i}+5\right)}{18}
$$

where $m$ is the number of groups of tied ranks, each with $t_{i}$ tied observations. The significance of trends is tested by comparing the standard variable $Z$ in Eq. 3 with the standard normal variate at the desired significance level, where the subtraction or addition of unity in Eq. 3 is a continuity correction (Kendall 1975).

$$
Z=\left\{\begin{array}{ccc}
\frac{S-1}{\sqrt{V_{o}(S)}} & \text { if } & S>0 \\
0 & \text { if } & S=0 \\
\frac{S+1}{\sqrt{V_{o}(S)}} & \text { if } & S<0
\end{array}\right.
$$

To accurately capture the auto-correlation structure of the 8,236 rainfall time series (284 grid cells and 29 variables), the Mann-Kendall test was modified using the approach of Hamed (2008) based on the scaling model (Koutsoyiannis 2003). The scaling effect can be formulated as follows: $\sigma_{\mathrm{k}}=\mathrm{k}^{\mathrm{H}} \sigma$ where $\sigma$ is the standard deviation of the original annual time series $\mathrm{X}_{\mathrm{i}}(\mathrm{i}=$ $1,2 \ldots), \sigma_{k}$ is the standard deviation of $Z_{i}^{(k)}, Z_{i}^{(k)}$ being an aggregated time series of $X_{i}$ at the kyear time step $(k=1,2, \ldots): \mathrm{Z}_{1}{ }^{(\mathrm{k})}=\mathrm{X}_{1}+\ldots+\mathrm{X}_{\mathrm{k}}, \mathrm{Z}_{\mathrm{i}}^{(\mathrm{k})}=\mathrm{X}_{(\mathrm{i}-1) \mathrm{k}+1}+\ldots+\mathrm{X}_{\mathrm{ik}} . H$ is the scaling coefficient, generally varying between 0.5 (no scaling effect) and 1 .

The computation of the modified Mann-Kendall test is presented in Hamed (2008). We summarize here only the main steps. Step 1: the original Mann-Kendall test is applied to the data. If the trend is not significant, no alteration of the original test is performed and the procedure ends here. Step 2: if the trend is significant, the effect of scaling on the trend significance is verified by estimating the scaling coefficient $H$ associated to the time series. If there is no scaling effect, the time series has a significant trend whose slope is estimated using the non-parametric Sen's slope estimator (Sen 1968) which has the advantage of not being sensitive to outliers. If there is a scaling effect, the variance of the test statistic is modified in step 3. Step 3: the variance of the modified test statistic is calculated using the auto-correlation coefficient introduced by Kendall and Stuart (1976), corrected for bias, standardized, and compared to the standard normal variate as in the original test. If the modified test indicates that the times series has a significant trend at the desired significance level, its slope is estimated using the Sen's slope estimator.

\subsection{Field significance}

A trend detection test applied to a point rainfall time series determines whether a trend exists at that location. However, because of the high variability of small-scale rainfall events, such a test 
does not indicate if a uniform trend is evident throughout an entire region of interest. The field significance, introduced by Vogel and Kroll (1989), indicates whether a significant regional trend, that could remain insignificant at individual stations, emerges from a group of stations in the same region (e.g. Lacombe et al. 2012b in Ghana, Lacombe et al. 2013 in Southeast Asia). Similar to the existence of auto-correlation, the presence of cross correlations in a network inflates the significance of a regional trend and impedes the analytical evaluation of field significance. To overcome this phenomenon, a resampling approach that computes the field significance in the presence of spatial correlation was adopted. The regional average Kendall's statistic $S_{m}$ was calculated as suggested by Douglas et al. (2000):

$$
S_{m}=\frac{1}{m} \sum_{k=1}^{m} S_{k}
$$

where $S_{k}$ is the statistic of the original Mann-Kendall test for the $k^{\text {th }}$ cell among the m grid cells of the selected region. An empirical cumulative distribution function of $S_{m}$ was generated by permuting years 10,000 times in the original data set, by calculating $S_{m}$ for each re-sampled data set, and by ranking the 10,000 values of $S_{m}$ in ascending order. This resampling process preserves the spatial correlation structure of the data. However, it does not account for the autocorrelation structure of the original data set which is not preserved by the permutation process. Consequently, original time series were pre-whitened according to Hamed's methodology (Hamed 2009), prior to being submitted to the regional test. The field significance associated with the regional Kendall's statistic $S_{m}^{h}$ computed from the historical data set was calculated using the Weibull plotting position formula:

$$
P\left(S_{m}<S_{m}^{h}\right)=\frac{r}{B+1}
$$

where $\mathrm{r}$ is the rank of $S_{m}^{h}$ and $B=10,000$. The regional Kendall test was applied for specific variables exhibiting unidirectional changes over homogeneous areas (areas 1, 2, 3 in Fig. 1; areas 4, 5 in Fig. 3) or across India (Figs. 1m and 2). Bracketed percentage values (Figs. 1, 2, and 3 ) indicate the field significance and direction of the computed regional trends.

\section{Results}

Slopes and statistical significances of the studied trends are displayed in Figs. 1, 2, and 3. Figures $1 \mathrm{a}-\mathrm{d}$ and $2 \mathrm{a}-\mathrm{d}$ correspond to seasonal and monthly rainfall depths, respectively. Figure $1 \mathrm{f}-\mathrm{i}$ and $\mathrm{k}-\mathrm{n}$ corresponds to seasonal number of rainy days and maximum daily rainfall, respectively. Figure $2 \mathrm{e}-\mathrm{h}$ and $2 \mathrm{i}-\mathrm{l}$ corresponds to monthly number of rainy days and maximum daily rainfall, respectively. Figure $1 \mathrm{e}$ and $\mathrm{j}$ corresponds to annual rainfall depth and number of rainy days, respectively. Figure 3 displays trends in the occurrence of the monsoon.

In winter, rainfall depths (Fig. 1a) do not exhibit any trends south of latitude $24^{\circ}$ and west of longitude $75^{\circ}$, consistent with the absence of precipitation in that area. Elsewhere, slopes are generally gentle, varying from -3.5 to $3.5 \mathrm{~mm}$.decade ${ }^{-1}$. The northeast and extreme southern parts of India are becoming drier, though with few statistically significant trends. Other areas are becoming wetter, especially between latitudes $11^{\circ}$ and $21^{\circ} \mathrm{N}$ where several significant rising trends are observed. The geographical distribution of trend directions in the number of rainy days (Fig. 1f) and maximum daily rainfall amount (Fig. 1k) are similar to that of rainfall depths.

During the pre-monsoon, local trends in rainfall depth (Fig. 1b) are predominantly negative in the southwest quarter of India (latitude $<23^{\circ}$; longitude $<82^{\circ}$, henceforth referred to as area 


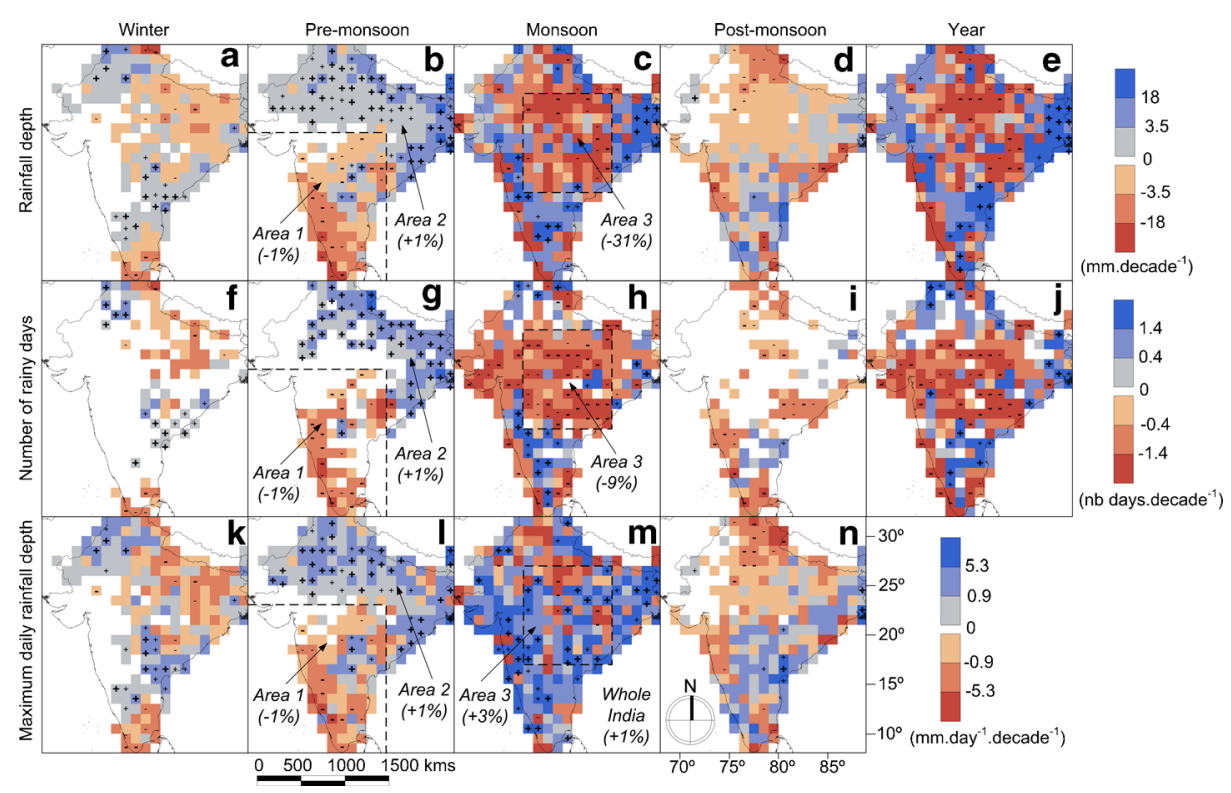

Fig. 1 Trends in seasonal and annual rainfall depths (a-e), number of rainy days $(\mathbf{f}-\mathbf{j})$ and seasonal maximum daily rainfall ( $\mathbf{k}-\mathbf{n})$ (variables 1 to 14). Signs indicate direction of statistically significant trends at cell level (bold font $=5 \%$ significance level. Normal font $=10 \%$ significance level). Bracketed percentages provide field significance level and direction of regional trends in respective areas

1) and positive elsewhere (henceforth referred to as area 2). Similar spatial patterns of change are observed for the number of rainy days (Fig. 1g) and for the maximum daily rainfall depths (Fig. 11). For these 3 variables, virtually uniform declining and rising regional trends in areas 1 and 2 , respectively, are $1 \%$ field significant.

During the monsoon, Central India $\left(17-27^{\circ} \mathrm{N}, 75-84^{\circ} \mathrm{E}\right.$; hereafter referred to as area 3$)$ is broadly becoming drier $\left(-15 \mathrm{~mm} \cdot\right.$ decade $^{-1}$ on average; field significance $\left.=31 \%\right)($ Fig. $1 \mathrm{c})$ with fewer rainy days $\left(-1.1\right.$ day.decade ${ }^{-1}$ on average; field significance $\left.=9 \%\right)$ (Fig. 1h). Maximum daily rainfall depth broadly increases $\left(+1.8 \mathrm{~mm}\right.$.day ${ }^{-1}$.decade ${ }^{-1}$ on average; field significance $=3 \%$ ) (Fig. $1 \mathrm{~m})$. Patterns of change are spatially heterogeneous outside of area 3, with a noticeable wetting tendency over most of the south peninsula and the northeast. Figure 2 shows that trends in monthly rainfall depths, number of rainy days and maximum daily rainfall are positive throughout India in June (Fig. 2a, e, i), with field significances for the whole of India of $1 \%, 13 \%$ and $1 \%$, respectively. In July, rainfall depth and the number of rainy days decrease (Fig. 2b, f). Changes in maximum rainy days are more heterogeneous during this month (Fig. 2j). No field significant regional trend is observed across the whole country in July (Fig. 2b, f, j). In August and September, patterns of change are more heterogeneous, roughly positive in the southwest and negative in the northeast, but consistent among the 3 categories of variables. A rising regional trend in maximum rainfall depth over the whole of India is $1 \%$ field significant in August (Fig. 2k) and during the monsoon (Fig. 1m), with average slopes of 0.5 and $2.7 \mathrm{~mm}$.day ${ }^{-1}$.decade ${ }^{-1}$, respectively. This spatially highly-significant uniform change is altered in some places with local negative trends but with minor effect on the regional signal.

Figure 3 displays changes in the occurrence of the monsoon. With the exception of the western side of the south peninsula where the onset of the monsoon (Fig. 3a) is delayed (positive trend), it happens earlier in the year (negative trend) over the rest of India. Most of the 


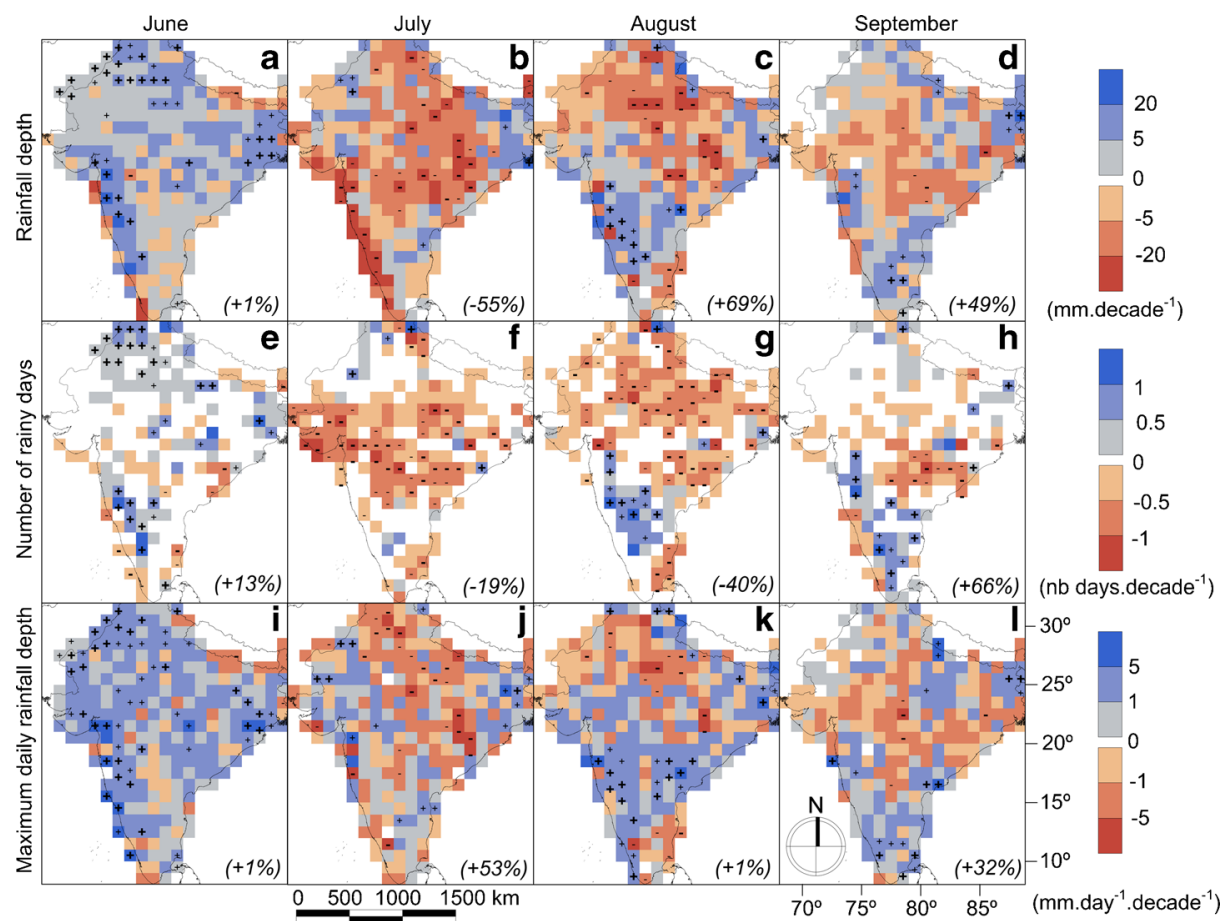

Fig. 2 Trends in monthly rainfall depth (a-d), number of rainy days (e-h) and maximum daily rainfall (i-l) during the monsoon (variables 15 to 26). Signs indicate direction of statistically significant trends at cell level (bold font $=5 \%$ significance level. Normal font $=10 \%$ significance level). Bracketed percentages provide field significance level and direction of regional trends over whole India

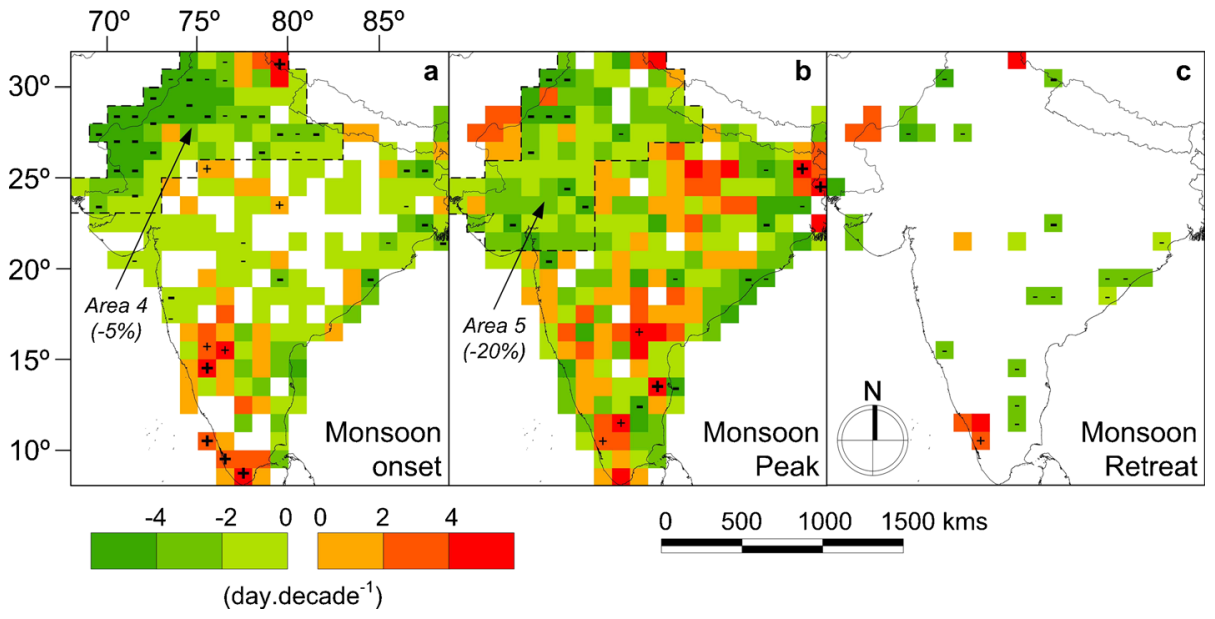

Fig. 3 Trends in the occurrence of the monsoon (variables 27 to 29). Signs indicate direction of statistically significant trends at cell level (bold font $=5 \%$ significance level. Normal font $=10 \%$ significance level). Bracketed percentages provide field significance level and direction of regional trends in respective areas 
significant negative trends are located in the northwest of the country. Minor changes in the monsoon onset are observed in Central India. Trends in the occurrence of the monsoon peak (Fig. 3b) follow similar spatial patterns, although positive trends (delays) are more frequent in Central-east India (Fig. 3b). The average trend slopes over the country are -0.7 and -0.9 day.decade ${ }^{-1}$ for the monsoon onset and peak, respectively. Very minor changes are observed in the monsoon retreat (Fig. 3c). Regional uniform negative trends in the monsoon onset in area 4 (Fig. 3a) and in the monsoon peak in area 5 (Fig. 3b) are $5 \%$ and $20 \%$ field significant, respectively. These delays are likely linked to the increased rainfall depth in Northern India during the pre-monsoon (Fig. 1b), which generalizes to the whole of India in June (Fig. 2a).

During the post-monsoon, the spatial distributions of trend directions in rainfall depths (Fig. 1d) and number of rainy days (Fig. 1i) are roughly similar to those observed during the monsoon, with gentler slope and lower statistical significance. Maximum daily rainfall (Fig. 1n) increased and decreased in the south-eastern and north-western regions of India, respectively.

Trends in annual rainfall depth (Fig. 1e) and the annual number of rainy days (Fig. 1j) are characterized by spatial patterns of change similar to those observed during the monsoon. Thus overall there is a drying trend across Central India and a wetting tendency over the south peninsula and the northeast, with a much more heterogeneous pattern across the rest of the country.

The averaged effect of the scaling behavior across India can be measured by the proportion of $5 \%$ significant trends, according to the original Mann-Kendall test, that becomes insignificant when submitted to the modified test. This proportion ranges from 0 (for September rainfall depth) to $54 \%$ (for post-monsoon rainfall depth) with an average value of $18 \%$ for the 29 studied variables. Figure S2 (online resource) illustrates detailed results at the level of individual grid cells.

\section{Discussion}

This study clarifies apparent contradictions between our results and previous studies and reviews available knowledge on recent atmospheric disturbances, mainly anthropogenic, possibly explaining the trends observed.

The decrease in annual and monsoon rainfall depth in central India (Fig. 1c, e) corroborates previous findings from seven different studies (Table 1). The delay in the monsoon onset, particularly significant in northern India (Fig. 3a), apparently contradicts the results of Duncan et al. (2013). A map of trend slopes obtained by the latter could reveal greater consistency. Results related to the controversial increase in monsoon extreme rainfall (Goswami et al. 2006; Ghosh et al. 2009, 2012) show that field significance levels are test-dependent. The $3 \%$-fieldsignificant increase in monsoon maximum daily rainfall observed in central India (area 3 in Fig. $1 \mathrm{~m}$ ) supports the results of Goswami et al. (2006), and our country-wide $1 \%$-fieldsignificant rising trend is consistent with the $1 \%$-significant rising trend in the spatial average of annual maxima over India identified by Ghosh et al. (2012). However, Ghosh et al. (2012), referring to Ghosh et al. (2009), claimed a lack of significant uniform trend in rainfall extremes at the $1 \%$ field significance level over India. The greater field significance level that we observed, likely originates from the different test that we used. The test introduced by Livezey and Chen (1983) and used by Ghosh et al. (2009) aims at testing the hypothesis " $\mathrm{H}_{0}$ : data from all sites are stationary" and thus, only considers local trends above a given significance level in the regional assessment. The regional Kendall statistic (Douglas et al. 2000) used here aims to 
detect a uniform signal in the whole distribution of trends in the studied area. This could result in field significances higher than the significance observed at each individual cell of the area. However, the regional Kendall test, like any other field significance test, is not sensitive to the spatial distributions of local trends within the tested area. Hence, it is not able to discern confined heterogeneities like those highlighted by Ghosh et al. (2009, 2012). This is why regional uniform trends should be characterized by both field significance assessments and visual inspection of trend slope maps. For example, area 2 (Fig. 1g) displays a more homogenous regional trend than the whole of India (Fig. 1m), although both are $1 \%$ field significant.

According to recent literature, higher atmospheric greenhouse gas concentration is the most likely driver of long-term trends in Indian rainfall over the last half century. Enhanced warming of the Himalayan-Gangetic region and the relatively smaller surface warming of the Indian Ocean is strengthening the inflow of moist air from the ocean toward the continent, particularly during the pre-monsoon, in April and May (Gautam et al. 2009). This phenomenon is enhanced by reduced snow cover over the Himalaya (Goes et al. 2005), which in turn reduces albedo and increases the land surface temperature. The Himalaya Chain acts as a barrier and most likely explains the rainfall increase observed in northern India during the pre-monsoon (Fig. 1b, g, 1). Because warm moist air transiting through India is drawn into the raising air over northern India, Central India receives less precipitation (Lau and Kim 2006), probably explaining the rainfall decrease in area 1 (Fig. 1b, g, 1). The positive effect of the enhanced thermal land-sea contrast on rainfall generalises to the whole of India in June (Fig. 2a), in response to stronger solar radiation and the reduction of snow-cover over the HimalayanTibetan Plateau. Increased rainfall in June leads to regional atmosphere-land feedback that cools the land surface (Bollasina et al. 2008), possibly explaining the subsequent rainfall reduction observed during the peak monsoon months (July-August) (Fig. 2b, c, f, g). The strongest rainfall decreases are observed in July, along the southwest coast of India (Fig. 2b). In this orographic region (the Western Ghats run parallel to a narrow coast, with an average elevation of $700 \mathrm{~m}$ ), the reduction of precipitation is likely due to the weakening of vertical velocities caused by upper tropospheric warming (Rajendran et al. 2012). In August, rainfall increases on the leeward side of the Western Ghats (where most of $5 \%$ significant positive trends are observed, cf. Fig. 2c), most likely in response to the moisture build-up effect in a warmer environment (Rajendran et al. 2012). The similarities between the spatial pattern of trends during the monsoon and the post-monsoon suggest that the drivers of rainfall change during these two seasons are identical.

The increase in monsoon maximum daily rainfall (Fig. 1m) may be attributable to the gradual increase in SST (Goswami et al. 2006). This causal link was re-examined and confirmed by Rajeevan et al. (2008). Therefore, the rise in the magnitude of extreme rainfall events is predominantly controlled by the increased atmospheric moisture content while the reduction of cumulative rainfall depth results from the weakening of the air flow in response to the reduced sea-land thermal contrast observed in July and August. However, Ghosh et al. (2009, 2012), who revisited the finding of Goswami et al. (2006), note that Central India includes some local pockets where rainfall trends are in the opposite direction (cf. in area 3 of Fig. 1c, h and $\mathrm{m}$ ) most likely because of local-scale changes such as urbanization and deforestation.

The increase in atmospheric aerosol concentrations is another important anthropogenic driver of long-term rainfall change. Since the 1930s, both $\mathrm{SO}_{2}$ and fossil fuel black carbon have increased 6-fold in response to the nearly 4-fold population increase and the accompanying industrialization in the Indo-Gangetic Plain (Ramanathan et al. 2005; Bollasina et al. 2011). Atmospheric aerosol loading generally starts in March-April and peaks in May. 
According to the "elevated heat pump" theory (Lau and Kim 2006), aerosols rising close to the southern slope of the Himalayas, warms the middle and upper troposphere, enhancing the large-scale meridional temperature gradient and so amplifying the meridional circulation, drawing in more moisture from the Indian Ocean. This phenomenon amplifies the premonsoon rainfall increase in northern India (cf. area 2 in Fig. 1b, g, 1). In addition, hygroscopic particles, such as sulfate aerosols, act as cloud condensation nuclei, promote cloud formation and may enhance precipitation. This mechanism could explain why the spatial distribution of high-concentration aerosol observed in May (cf. Fig. 1a in Bollasina et al. 2008) corresponds exactly with areas exhibiting positive rainfall trends during the pre-monsoon (Fig. 1b, g, 1). However, the complex character of climate dynamics controlled by subtle combinations of local and global natural and anthropogenic forcing, whose effects on atmospheric circulation are not yet totally understood, impedes the attribution of rainfall trends to aerosols (Turner and Annamalai 2012). For example, Bollasina et al. (2008) showed that excessive aerosols may lead to reduced precipitation in response to aerosol-induced warming and evaporation of the cloud layer. Known as the semi-direct effect, this phenomenon has the opposite effect to the elevated heat pump mechanism postulated by Lau and Kim (2006).

\section{Conclusion}

This study was driven by the apparent lack of consistency between the numerous recent climate studies focusing on rainfall trends in India and the difficulty of reconciling heterogeneous information generated by different methods. We have shown that when local and regional rainfall trends are accurately characterized (geographic delineation, appropriate statistical assessment and visual inspection of maps), a clearer picture emerges and agrees with atmospheric science studies reporting recent anthropogenic disturbances. The analyses also demonstrate that statistical methods applied to climate sciences still need improvement. This is particularly so in relation to field significance assessment of uniform regional changes when they include localized heterogeneities obviously not produced by chance but resulting from environmental alterations. Among the two main anthropogenic drivers of synoptic rainfall changes in India, greenhouse gas emission and aerosol emission, the former confidently explains our observations. Thus, it is to be expected that the rainfall trends we mapped, especially those with high field significance levels, will most likely continue in the near future since the atmosphere is expected to continue warming as greenhouse gas concentrations rise. Therefore, the maps created (Figs. 1, 2, and 3) could be used to anticipate future changes in water resource availability and, to some extent, agricultural production across the country.

Acknowledgments This work was initiated as part of the World Wide Fund (WWF)-India's "Living Ganga Programme". It was funded by the CGIAR research programme on Climate Change, Agriculture and Food Security (CCAFS) and by WWF-India. The authors thank the Indian Meteorological Department for the provision of rainfall data. The authors are grateful to Luna Bharati and Nitin Kaushal for their support and to Shwu Jiau Teoh and Sajid Pareeth who pre-processed the rainfall data.

Author attribution GL designed the problem, developed codes and performed the analysis. GL prepared the figures and interpreted the results with comments from MM. GL wrote the paper with input from MM.

Open Access This article is distributed under the terms of the Creative Commons Attribution License which permits any use, distribution, and reproduction in any medium, provided the original author(s) and the source are credited. 


\section{References}

Bollasina M, Ming Y, Ramaswamy V (2011) Anthropogenic aerosols and the weakening of the South Asian summer monsoon. Science 334:502-505

Bollasina M, Nigam S, Lau KM (2008) Absorbing aerosols and summer monsoon evolution over South Asia: An observational portrayal. J Clim 21:3221-3239

CIA (2012) The World factbook. https:/www.cia.gov/library/publications/the-world-factbook/geos/in.html Accessed 6 January 2014

Cox DR, Stuart A (1955) Some quick sign tests for trend in location and dispersion. Biometrika 42:80-95

Dash SK, Jenamani RK, Kalsi SR, Panda SK (2007) Some evidence of climate change in twentieth century India. Clim Chang 85:299-321

Douglas EM, Vogel RM, Kroll CN (2000) Trends in floods and low flows in the United States: impact of spatial correlation. J Hydrol 240:90-105

Duncan JMA, Dash J, Atkinson PM (2013) Analysing temporal trends in the Indian summer monsoon and its variability at a fine spatial resolution. Clim Chang 117:119-131

Gadgil S, Gadgil S (2006) The Indian monsoon, GDP and agriculture. Econ Polit wkly 41(47):4887-4895

Gautam R, Hsu NC, Lau KM, Tsay SC, Kafatos M (2009) Enhanced pre-monsoon warming over the HimalayanGangetic region from 1979 to 2007. Geophys Res Lett 36:L07704

Ghosh S, Das D, Kao SC, Ganguly AR (2012) Lack of uniform trends but increasing spatial variability in observed Indian rainfall extremes. Nature Clim Chang. doi:10.1038/Nclimate1327

Ghosh S, Luniya V, Gupta A (2009) Trend analysis of Indian summer monsoon rainfall at different spatial scales. Atmos Sci Lett 10:285-290

Goes JI, Thoppil PG, Gomes HR, Fasullo JT (2005) Warming of the Eurasian landmass is making the Arabian Sea more productive. Science 308:545-547

Goswami BN, Venugopal V, Sengupta D, Madhusoodanan MS, Xavier PK (2006) Increasing trend of extreme rain events over India in a warming environment. Science 314:1442-1445

Guhathakurta P, Rajeevan M (2008) Trends in the rainfall pattern over India. Int J Climatol 28:1453-1469

Hamed KH (2008) Trend detection in hydrologic data: The Mann-Kendall trend test under the scaling hypothesis. J Hydrol 349:350-363

Hamed KH (2009) Enhancing the effectiveness of prewhitening in trend analysis of hydrologic data. J Hydrol 368:143-155

Hurst HE (1951) Long term storage capacities of reservoirs. Trans Am Soc Civ Eng 116:776-808

Jain SK, Kumar V (2012) Trend analysis of rainfall and temperature data for India. Curr Sci 102(1):37-49

Kendall MG (1975) Rank correlation methods. Griffin, London

Kendall MG, Stuart A (1976) The advanced theory of statistics. Distribution Theory (1), Griffin

Koutsoyiannis D (2003) Climatic change, the hurst phenomenon, and hydrological statistics. Hydrol Sci J 48(1):3-24

Krishnamurthy CKB, Lall U, Kwon HH (2009) Changing frequency and intensity of rainfall extremes over India from 1951 to 2003. J Clim 22:4737-4746

Kucharski F et al (2009) The CLIVAR C20C project: skill of simulating Indian monsoon rainfall on interannual to decadal timescales. Does GHG forcing play a role? Clim Dyn 33(5):615-627

Kumar KK, Rajagopalan B, Hoerling M, Bates G, Cane M (2006) Unraveling the mystery of Indian Monsoon failure during El Niño. Science 314:115-119

Kumar V, Jain SK (2011) Trends in rainfall amount and number of rainy days in river basins of India (19512004). Hydrol Res 42(4):290-306

Kumar V, Jain SK, Singh Y (2010) Analysis of long-term rainfall trends in India. Hydrol Sci J 55(4):484-496

Lacombe G, Hoanh CT, Smakhtin V (2012a) Multi-year variability or unidirectional trends? Mapping long-term precipitation and temperature changes in continental Southeast Asia using PRECIS regional climate model. Clim Chang 113(2):285-299

Lacombe G, McCartney M, Forkuor G (2012b) Drying climate in Ghana over the period 1960-2005: evidence from the resampling-based Mann-Kendall test at local and regional levels. Hydrol Sci J 57(8):1594-1609

Lacombe G, Smakhtin V, Hoanh CT (2013) Wetting tendency in the central Mekong basin consistent with climatechange-induced atmospheric disturbances already observed in East Asia. Theor Appl Climatol 111(1-2):251-263

Lau KM, Kim KM (2006) Observational relationships between aerosol and Asian monsoon rainfall, and circulation. Geophys Res Lett 33, L21810

Livezey RE, Chen WY (1983) Statistical field significance and its determination by Monter Carlo techniques. Mon Weather Rev 111:46-59

Pal I, Al-Tabbaa A (2011) Assessing seasonal precipitation trends in India using parametric and non-parametric statistical techniques. Theor Appl Climatol 103:1-11

Rajeevan M, Bhate J, Jaswal AK (2008) Analysis of variability and trends of extreme rainfall events over India using 104 years of gridded daily rainfall data. Geophys Res Lett 35(18), L18707 
Rajeevan M, Bhate J, Kale JD, Lal B (2006) High resolution daily gridded rainfall for the Indian region: Analysis of break and active monsoon spells. Curr Sci 91(3):296-306

Rajendran K, Kitoh A, Srinivasan J, Mizuta R, Krishnan R (2012) Monsoon circulation interaction with Western Ghats orography under changing climate. Theor Appl Climatol 110:555-571

Ramanathan V, Chung C, Kim D, Bettge T, Buja L, Kiehl JT, Washington WM, Fu Q, Sikka DR (2005) Atmospheric brown clouds: Impacts on South Asian climate and hydrologic cycle. PNAS 102:5326-5333

Ranade A, Singh N, Singh HN, Sontakke NA (2008) On variability of hydrological wet season, seasonal rainfall and rainwater potential of the river basins of India (1813-2006). J Hydrol Res Dev 23:79-108

Renard B et al (2008) Regional methods for trend detection: Assessing field significance and regional consistency. Water Resour Res 44, W08419

Sen PK (1968) Estimates of the regression coefficient based on Kendall's tau. J Am Stat Assoc 63:1379-1389

Singh N, Sontakke NA, Singh HN, Pandey AK (2005) Recent trend in spatiotemporal variation of rainfall over India - an investigation into basin-scale rainfall fluctuations. In: Franks S, Wagener T, Bogh E, Gupta HV, Bastidas L, Nobre C, Galvao C (eds) Regional hydrological impacts of climatic change-hydroclimatic variability. 1AHS, Brazil, pp 273-282, Publication 296

Turner AG, Annamalai H (2012) Climate change and the South Asian summer monsoon. Nature Clim Chang. doi:10.1038/Nclimate1495

Vogel RM, Kroll CN (1989) Low-flow frequency analysis using probability plot correlation coefficients. J Water Resour Plan Manag 115:338-357 